\title{
A novel freeform extrusion fabrication process for producing solid ceramic components with uniform layered radiation drying
}

\author{
Amir Ghazanfari ${ }^{\mathrm{a},}{ }^{*}$, Wenbin $\mathrm{Li}^{\mathrm{a}}$, Ming C. Leu ${ }^{\mathrm{a}}$, Gregory E. Hilmas ${ }^{\mathrm{b}}$ \\ ${ }^{a}$ Department of Mechanical and Aerospace Engineering, Missouri University of Science and \\ Technology, Rolla, MO, USA \\ ${ }^{\mathrm{b}}$ Department of Materials Science and Engineering, Missouri University of Science and \\ Technology, Rolla, MO, USA
}

\begin{abstract}
$\underline{\text { Abstract }}$
An extrusion-based additive manufacturing process, called the Ceramic On-Demand Extrusion (CODE) process, for producing three-dimensional ceramic components with near theoretical densityis introduced in this paper.In this process, an aqueous paste of ceramic particles with a very low binder content ( $<1 \mathrm{vol} \%)$ is extruded through a moving nozzle at room temperature. After a layer is deposited, it is surrounded by oil (to a level just below the top surface of most recent layer) to preclude non-uniform evaporation from the sides. Infrared radiation is then used to partially, and uniformly, dry the just-deposited layer so that the yield stress of the paste increases and the part maintains its shape. The same procedure is repeated for every layer until part fabrication is completed. Several sample parts for various applications were produced using this process and their properties were obtained. The results indicate that the proposed method enables fabrication of large, dense ceramic parts with complex geometries.
\end{abstract}

Keywords:3D printing; extrusion freeforming;fused deposition; robocasting;radiation drying.

\section{Introduction}

Several additive manufacturing techniques have been developed or modified to fabricate three-dimensionalceramic components, including 3D Printing[1], Ink-jet Printing[2], Selective Laser Sintering (SLS)[3], Stereolithography (SLA)[4], Laminated Object Manufacturing (LOM)[5], and extrusion-based techniques. All of these techniques involve adding ceramic materials layer by layer. Acomprehensive review on additive manufacturing of ceramic-based materials was recently published byTravitzky et al. [6].

Extrusion-based methods are among the most popular approachesfor freeform fabrication of ceramic components due to the simplicity and low cost of their fabrication system, high density of their fabricated parts, their capability of producing parts with multiple materials [7] and/or as functionally graded materials [8,9], and the low amount of material wasted during processing. Majorextrusion-based processes includeExtrusion Freeform Fabrication (EFF), Fused Deposition of Ceramics (FDC), Robocasting (RC), and Freeze-form Extrusion Fabrication (FEF).

EFF [10]was the first technique to utilize extrusion of ceramic slurries (organic-based) to produce three-dimensionalcomponents. Slurries of alumina in liquid acrylic monomers

\footnotetext{
* Corresponding author (amir.ghazanfari@mst.edu).
} 
wereprepared and deposited onto a heated platen to retain their shape. The process was further improved and more complex geometries with other materials such as silicon nitride were fabricated[11]. EFF is also the first extrusion-based process to produce ceramic-based functionally graded materials such as ceramic oxides graded to Inconel or stainless steel[8].

Danforth introduced the concept of FDC[12]. They used a commercial Fused Deposition Modeling (FDM)system fromStratasys Inc. (Eden Prairie, MN, USA) to extrude ceramic-loaded thermoplastic filaments.The filament was liquefied, extruded, and re-solidified to retain its shape. Since then, they have significantly improved their process and have been able to produce high quality parts made of different materials for various applications, especially sensors and actuators[13-17].

$\mathrm{RC}[18,19]$ is a renowned freeform extrusion fabrication process of ceramics. The main advantage of RC over EFF and FDC is the use of a lower amount of binder in the feedstock $(<10$ wt $\%$ vs. $>30 \mathrm{wt} \%$ ) which facilitates pre-processing and post-processing. In this process, typically an aqueous suspension from ceramic materials(e.g. alumina, silica, lead zirconate titanate, hydroxyapatite, silicon carbide, and silicon nitride) is prepared and extrudedon to a hot plate to dry and maintain its shape. RC can produce grid or thin-wall structures for various applications, especially bio-fabrication [20-24].

In the FEF process[25], a high solids loading (>50 vol\%) aqueous paste containing 1-4 vol\% organic additives is extruded in a freezing environment to solidify the paste after itsdeposition. Freeze drying is then used to remove the water content before sintering. This process is also capable of producing complex and functionally graded parts made of different materials such as alumina, zirconium diboride, boron carbide, zirconium carbide, and bio-active glasses [26-29]. Several advanced control algorithms were also implemented to enhance the performance of extrusion-on-demand and consistency in paste flowrate[30-33].

While the latter additive manufacturing processes have theirrespective advantages, they also have limitations. The binder removal procedures for EFF and FDC is difficult and timeconsuming, and sometimes causes severe warpage or other defects. It might require multiple cycles with different atmospheres. For FDC, the feedstock preparation is also burdensome and requires several steps. The filament must also maintain a very high dimensional tolerance $(<2 \%$ variations in diameter) to ensure consistent flowrates[17]. Although parts of multiple materials could be produced, FDC is not capable of mixing them and fabricating functionally graded parts. It is difficult for RC to build large solid parts due to non-uniform drying which causes warpage and cracks in the parts. Furthermore, due to inconsistency in extrudate flowrate and presence of air bubbles in the suspension, the products are not fully dense and their mechanical strength does not match that of parts produced by EFF and FDC. The latter challenges add to ice crystal formation during the freezing process, and weak layer-to-layer bonding in FEF to further reducethe relative density and mechanical properties after binder removal and sintering. Finally, all these extrusion-based processes suffer from nozzle clogging due to ceramic powderagglomerates and binder agglomerates in the feedstock, and freezing or drying of paste inside the nozzle.

In an attempt to overcome the above limitations, the Ceramic On-Demand Extrusion (CODE) process is proposed in this paper. The feedstock of this process is an aqueous paste prepared in a 
similar fashion as in FEF. The paste is then extruded at room temperature through a progressive cavity pumpbased extruder to guarantee a consistent flowrate. The solidification of each layer is achieved via partial drying using an infrared lamp, with a liquid oil surrounding the part. This precludes non-uniform evaporation from the sides of the part during the radiation drying and enables fabrication of large solid parts with complex geometries. Moreover, the proposed method reduces the risk of part warpage and crack formation during the binder removal step. Another advantage of this process is that it produces three-dimensional green bodies that can be machined to increase the surface smoothness and dimensional accuracy of the printed parts prior to sintering.Several sample parts are fabricated and their properties are studied.

\section{CeramicOn-Demand Extrusion (CODE) Process}

\subsection{Process Overview}

In the CODE processproposed in this paper, viscous suspensions (pastes) of ceramic particles are extruded at controlled flowrates through a circular nozzle. The nozzle is attached to a motion system which is capable of moving in X, Y and Z directions through G \& M code commands provided by an indigenously developed tool-path planning software. The extrudate is deposited on a substrate located in a tank designed to hold a fluid medium. Once the deposition of each layer is completed, a liquid feeding subsystem pumps oil into the tank surrounding the layer to preclude undesirable water evaporation from the sides of the deposited layers. The level of the liquid is controlled so that it is maintained at a level that is just below the top surface of the part being fabricated. Infrared radiation is then used to uniformly dry the deposited layer so that the part being fabricated can maintain its shape when the next layers are being deposited on top of it. The part is fabricated in a layer-by-layer fashion by repeating the layered deposition followed by radiation drying with a liquid surrounding the already deposited layers during the part fabrication process. A schematic of the process is shown in Figure 1.Once the fabrication process is completed, the remaining water content in the fabricated part is removed further by bulk drying to obtain green parts. The post-processing includes removing the binder content and sintering the part at elevated temperatures.

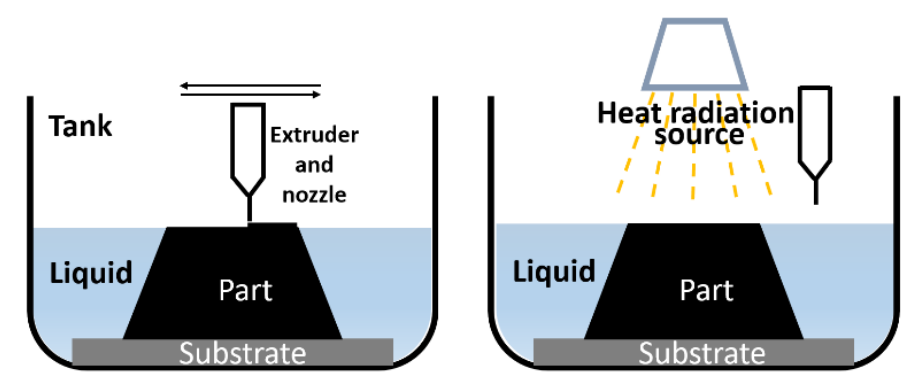

Figure 1. Schematic of the Ceramic On-Demand Extrusion process.

For fabricating components that have external/internal features such as overhangs, conformal cooling channels, etc. and cannot be fabricated without the use of support,an inorganic sacrificial material $\left(\mathrm{CaCO}_{3}\right)$ is used to build a support structure. The sacrificial material decomposes during sintering and then dissolves in water or acid afterwards [34]. 


\subsection{Tool-Path Planning Software}

Because of limitations of commercial tool-path planning software, a program was developed using Matlab programming language. It is capable of reading the geometry of the part in Stereolithography format (STL), preparing and illustrating the tool-path for each layer, and generating a G \& M code for the fabrication machine. The program takes the user inputs (layer thickness, raster spacing, dwell time for the gantry system before each starting point, dwell time for the gantry system after printing each layer, early stop distance, extrusion speed, table speed, distance traveled by the gantry system in Z-direction after each stop, etc.) along with the STL file, slices it by calculating its intersections with constant- $Z$ planes, designs tool-path for each layer and generates the required $\mathrm{G} \& \mathrm{M}$ code for the machine to fabricate the part. The program consists of the following subroutines:

Reading and slicing subroutine: a subroutine was developed in Matlab capable of reading an STL file and cutting it into a desired number of slices (layers) with adjustable accuracy. To obtain the slices for each value of Z-coordinate, the subroutine first checks whether there is an intersection between the Z-plane and each triangle in the STL file. If there is an intersection, it finds the two sides that intersect with the plane. Then, it employs analytical geometry equations to find the intersection point of each side with the plane. Next, it connects the two points to form a segment and continues this procedure to find all segments and determine layer boundaries.

Rastering subroutine: to print each layer, the gantry system should be able to follow a suitable path and fill in boundaries of each layer. A subroutine was developed in Matlab that is capable of identifying boundaries of each slice (produced by the previous subroutine) and generating a tool-path for the gantry system to follow. The rasters could be either in X or Y direction. Assuming rasters in $X$ direction are requested by the user, the subroutine first checks whether there is an intersection between a constant-Y line and each segment in the current layer. If there is an intersection, it employs analytical geometry equations to find the intersection and stores the values in the so-called "t-matrix". Next, it orders " $t$ " so that printing starts at the bottom left of the layer and the first line of material is printed from left to right; then, forthe case of the presence of several lines in the next Y-level, the left-most one is chosen and printed from right to left. This procedure is continued until the top-most line of the layer is printed (see Figure 2(a)). Then, the same procedure is repeated for the remaining rasters until all rasters are printed (Figure 2 (b) and (c)). This subroutine is also capable of adaptively changing the line width to increase the dimensional accuracy and/or the productivity as proposed in [35].

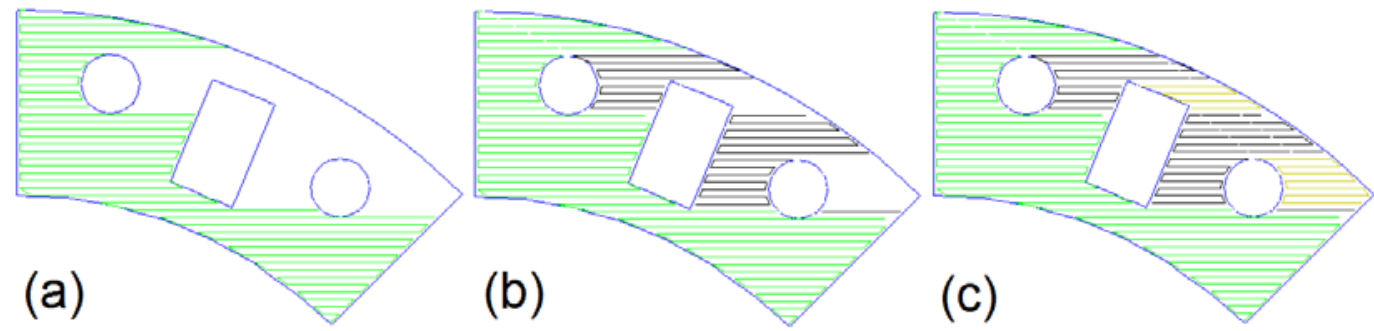

Figure 2. Sequence of printing rasters.

G \& M code generating subroutine: the output of the previous subroutine is the path that the gantry system needs to follow and command signals to other subsystems of the fabrication 
machine. Another subroutine was developed in Matlab capable of producing a text file that contains G \& M codes (i.e. tool-path, starts and stops, dwell times, table speed, etc.).

\subsection{Paste Preparation}

A nominally60 vol\% solids loading alumina paste was prepared using acommercially available alumina powder (A-16SG, Almatis Inc., Leetsdale, PA, USA) in all of the experiments in this study. Other materials including zirconia, silica, boron carbide, 13-93 bioactive glass, zirconium carbide,zirconium diboride, etc. could be potentially used in CODE and are currently under investigation.

The paste was composed of alumina powder, deionized water, ammonium polymethacrylate(DARVAN® C-N, Vanderbilt Minerals, Norwalk, CT, USA), and methylcellulose (MethocelJ5M S,Dow Chemical Company, Midland, MI, USA). For parts which were intended to be freeze dried (as will be discussed in section 2.6.1), $20 \mathrm{wt} \%$ glycerol was used as suggested by Sofie and Dogan[36]to prevent the growth of large ice crystals and freezing defects associated with water crystallization.The alumina powder was dispersed in water using0.94 g Darvan C per $100 \mathrm{~g}$ of powder,and then ball-milled for 15 hours to break up agglomerates and to produce a uniform mixture. Methylcellulose ( $<1$ vol\%) was dissolved in water and was used as a binder to increase paste viscosity and to assist in forming a stronger green body after drying. A vacuum mixer (Model F, Whip Mix,Louisville, KY, USA) was employed for 12 minutes to mix the paste homogeneously without introducing air bubbles. Finally, a vibratory table (Syntron Material Handling, Saltillo, MS, USA) was used for to remove the remaining air bubbles.

\subsection{Drying Behavior of Paste Films}

Since the CODE process involves layer-wisepartial drying of ceramic paste, a set of experiments was designed and carried out to study the drying behavior of layers during the process. For a given layer thickness and paste properties, the evaporation rate and drying time should be adjusted. If the evaporation rate is too high, cracks may form on the layer surface or the bonding between two successive layers might become weak. On the other hand, if the evaporation rate is too low, the increase in the yield stress of the paste might not be sufficient to maintain the shape of the part or the required drying time might have to be increased too much, which in turn results in unacceptably long fabrication times. A similar argument holds for the drying time. If the drying time is too high, crack formation or weak layer boning may be observed, and if it is too low, the part cannot maintain its shape and deforms. Accordingly, the highest evaporation rate that does not result in crack formation, and the shortest drying time that does not result in part deformation, are desirable in the CODE process.

Crack formation in a layer during drying is the result of stresses caused by pressure gradients in the liquid phase as well as biaxial tension exerted by the substrate. When a portion of the liquid phase in the paste evaporates from the surface, the liquid "stretches" (driven mainly by capillary forces) to cover the dry region. This produces tension in the liquid, which varies in the thickness directionif the evaporation rate is fast relative to the transport rate of the liquid. This pressure gradient may cause warping and/or cracking if thepart body is not stiff and/or strong enough. Furthermore, in the first phase of drying (constant rate period), there is a reduction in the volume 
of the paste equal to the amount of water evaporated. However, during the drying of a layer on a substrate, the paste cannot shrink at the substrate-paste interface due to adhesion between the two layers. This causes biaxial tension in the paste which increases in the thickness direction.A comprehensive discussion of the drying phenomenonis provided in [37].

The total stress depends on layer thickness, surface tension, evaporation rate, viscosity, permeability, solids loading, etc. Whether or not this stress results in cracks depends on the fracture toughness, Young's modulus and Poisson's ratio of the paste, whose values change during drying. Lange [38]used Griffith's criterion to calculate the critical thickness of a drying film above which the crack formation initiates. Based on his calculations, the critical thickness is

$$
h_{c}=\frac{2 G_{c} E^{*}}{Z \sigma^{2}}
$$

where $G_{c}$ is the critical stain energy release rate (a measure of fracture toughness), $E^{*}=E /(1-v)$, where $E$ is the Young's modulus and $v$ is the Poisson's ratio, $\sigma$ is the stress and $Z$ is a shape factor. Thus, to avoid cracking, one can either improve the strength of the paste (e.g. by adding more binder) or reduce the stresses (e.g. by adding surfactants to reduce surface tension or slow drying process of the paste).

Many researchers have studied the drying behavior of ceramic suspension films and examined the effect of various parameters on crack formation. Carreras et al. [39] investigated the effects of solution chemistry, binder and binder crosslinking on the critical cracking thickness of films obtained by drying aqueous alumina suspensions. Their results indicate that the critical cracking thicknesssignificantly increases by crosslinking poly (vinyl alcohol) used as binder. Holmes et al.[40]used a laser speckle interferometry and experimentally studied the onset of cracking during drying of alumina suspensions cast onto a substrate to better understand this phenomenon. Contrary to other investigations, they postulated that the driving force for cracking actually arises from a misfit strain that occurs when the repulsive layers between the particles collapse completely and after the particles have adhered to the substrate. Chiu et al. [41] examined the effect of processing variables on cracking behavior of binder-free granular ceramic films. These variables included particle size, liquid surface tension, evaporation rate, dispersion stability, and sedimentation time. They also examined various types of substrates including glass, Teflon and a pool of liquid mercury. For each case, a critical thickness was obtained above which, cracking occurred.

In the current study, layers of alumina paste were spread on glass substrates and dried using the same infrared heating lamp employed in the CODE process. The objective of these experiments was to study the effect of layer thickness and drying conditions on crack formation and evaporation rates.

The layer thickness can vary between $\sim 100 \mu \mathrm{m}$ and $\sim 800 \mu \mathrm{m}$ in the CODE process. Accordingly, layers of $250 \mu \mathrm{m}$ and $500 \mu \mathrm{m}$ were chosen to be spread on substrates. For each thickness, three different drying conditions were investigated. In the first set of tests, samples were dried at room condition $\left(\sim 23{ }^{\circ} \mathrm{C}, \sim 55 \%\right.$ relative humidity, $\sim 0 \mathrm{~m} / \mathrm{s}$ flow of air). In the second set of tests, the same lamp employed in the CODE process (375 Watt, 120 Volt, BR40 Clear Heat Lamp Reflector Bulb, Westinghouse Electric Corporation, Philadelphia, PA, USA) was 
used at a distance of $0.21 \mathrm{~m}$ (from lamp filament to substrate) to dry the paste. In the third set of tests, the distance was reduced to $0.16 \mathrm{~m}$ to increase the evaporation rate. Every experiment was repeated three times and an average was taken. Thus, a total number of 18 samples (2 (thicknesses) $\times 3$ (drying conditions) $\times 3$ (repetitions)) were tested.

The amount of evaporated water was calculated based on the reduction of the mass of the spread paste as a function of time. A digital analytical balance with $0.1 \mathrm{mg}$ readability was continually used to measure the changes in the mass of the paste. The measurement times were also recorded to calculate the evaporation rate as well as amount of evaporation. The instantaneous water content, $W$ (wt\%), in the paste was obtained using Equation (2):

$$
W=\frac{M_{t}-M_{d}}{M_{t}}
$$

where $M_{t}$ is the instantaneous total mass of the paste (i.e. the reading from the digital analytical balance) and $M_{d}$ is the dry mass of the paste (measured after it is totally dried in an oven).

The most influential parameter in these experiments was the heat flux density $\left(\overrightarrow{J_{q}}\right)$ from the lamp at the surface of the paste. The value of heat flux density was estimated using Equation (3):

$$
J_{q}=\frac{K_{1} K_{2} P \cos \alpha}{4 \pi d^{2}}
$$

where $K_{1}$ is the radiation coefficient of the lamp (i.e. the fraction of the input electrical energy transformed to radiation energy), $K_{2}$ is the projection coefficient (i.e. the fraction of the radiation energy projected to the paste),P is the power of the lamp, $\alpha$ is the angle of incidence, and $d$ is the distance between lamp filament and paste. For the current experimental setup, $K_{1}$ was $\sim 80 \%$ [42], $K_{2}$ was estimated to be $\sim 300 \%$ based on the shape of the lamp shading; $P$ and $\alpha$ were $375 \mathrm{~W}$ and $\sim 0^{\circ}$, respectively. Thus, for $d=0.21$, the value of heat flux density was $\sim 1.6 \mathrm{~kW} / \mathrm{m}^{2}$ and, for $d=0.16$, it was $\sim 2.8 \mathrm{~kW} / \mathrm{m}^{2}$.

The results are illustrated in Figure 3 and Figure 4 for $250 \mu \mathrm{m}$ and $500 \mu \mathrm{m}$ thicknesses, respectively. Films with $500 \mu \mathrm{m}$ thickness, and the highest evaporation rate, crackedat $\sim 200 \mathrm{~s}$ after $\sim 25 \%$ water was evaporated. A sample with cracks is shown inFigure 5 . No cracks were observed in any other samples from the remaining five data sets, even after drying was complete.The initial drying rates (i.e. slopes of the evaporation curves) are given in Table 1. As expected, both heat flux density and layer thickness played an important role in drying of the films. Increasing the heat flux density expedites the drying process. By increasing the thickness, the volume of the paste increases without a change in surface area. Thus, the amount of water evaporated per unit volume of paste decreases. 


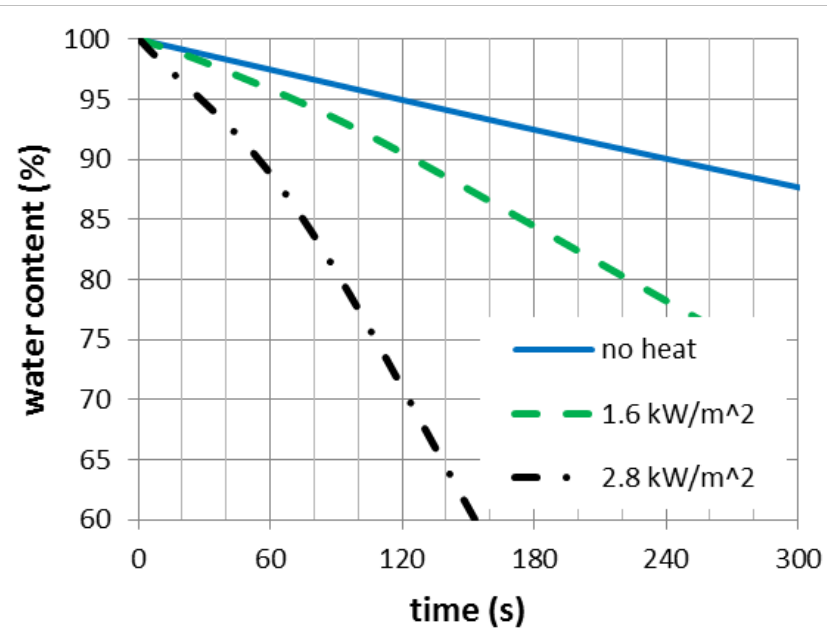

Figure 3. Evaporation curves for $250 \mu \mathrm{m}$ layer.

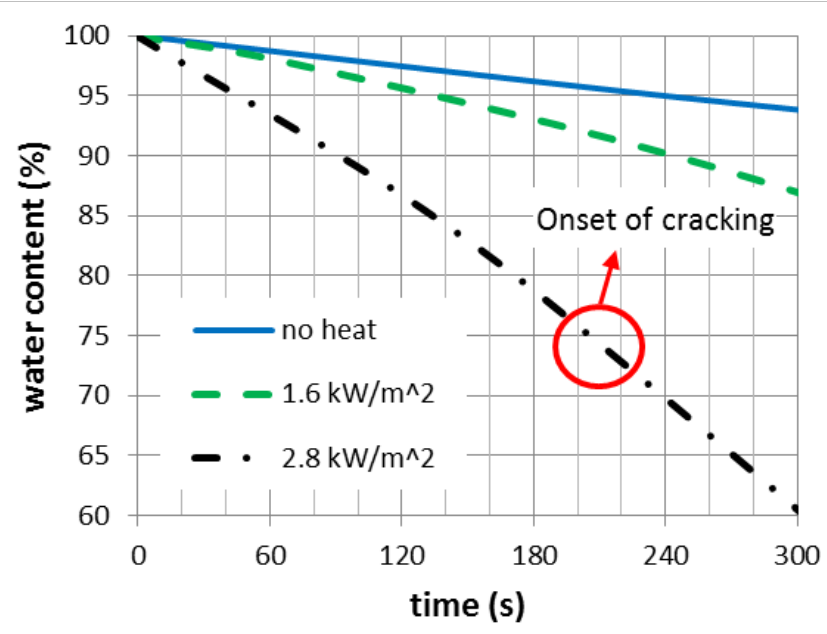

Figure 4. Evaporation curves for $500 \mu \mathrm{m}$ layer.

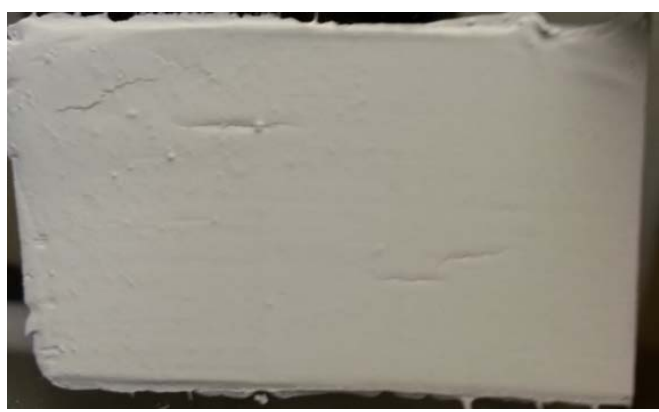

Figure 5. Cracks as a result of fast drying.

Table 1. Initial drying rates for films.

\begin{tabular}{|c|c|c|}
\hline & $\mathbf{2 5 0} \boldsymbol{\mu m}$ layer & $\mathbf{5 0 0} \boldsymbol{\mu m}$ layer \\
\hline No heat & $2.5 \% / \mathrm{min}$ & $1.2 \% / \mathrm{min}$ \\
\hline $\mathbf{1 . 6} \mathbf{~ k W} / \mathbf{m}^{2}$ & $4.3 \% / \mathrm{min}$ & $2.1 \% / \mathrm{min}$ \\
\hline $\mathbf{2 . 8} \mathbf{~ k W} / \mathbf{m}^{2}$ & $10.9 \% / \mathrm{min}$ & $6.9 \% / \mathrm{min}$ \\
\hline
\end{tabular}


The results of these experiments were used to tune the process parameters as will be discussed in section 2.5.5. These parameters include the distance between the radiant heat source and the last deposited layer, which corresponds to evaporation rate, and the dwell time between successive layers, which is approximately equal to drying time (since the lamp is radiating only during this time). It should be noted that these results are independent of the area and shape of the layers and can be used for any arbitrary layer geometry. In other words, the side area of a layer is negligible compared to its top area; thus, the amount of evaporated water is proportional to the area of the layer, and mass of evaporated water per unit mass of paste is independent of the area of the layer.

During the fabrication process, the new layer is deposited on the previous layer. Since the previously deposited layer is not rigid, as opposed to the glass substrate, the value of the biaxial tension exerted from the previous layer is lower than the glass. Another inaccuracy of these experiments is that in the CODE process, a portion of the heat received from the lamp is transferred to the previous layers whereas in these experiments, the heat was transferred to the glass.

\subsection{Fabrication System}

The experimental setup consists of a motion subsystem (gantry) capable of moving in three directions, extrusion devices mounted on the gantry and capable of extruding viscous ceramic paste at constant flowrates, an oil feeding device capable of controlling the level of oil in the tank, and an infrared heating subsystem capable of moving the infrared lamp and turning it on and off.The gantry iscontrolled by a motion card (Delta Tau Data Systems Inc., Chatsworth, CA, USA) whereas all other subsystems are controlled by a real-time control subsystemwith LabVIEW (National Instruments Corp., Austin, TX, USA).

\subsubsection{Motion Subsystem}

The gantry consists of threeorthogonal linear drives (Velmex, Bloomfield, NY, USA), each with a $508 \mathrm{~mm}$ travel range. The $\mathrm{X}$-axis consists of two parallel slides and is used to support the $\mathrm{Y}$-axis. The use of two parallel slides provides a smoother and more stable motion, thus providing a larger work space for part fabrication. The Z-axis is mounted on the Y-axis, and the extrusion mechanism is mounted on the Z-axis. Each of these axes has limit switches on both ends. Four DC servomotors (PMA22B, Pacific Scientific, Rockford, IL, USA), each with a resolver for position feedback at a resolution of 1000 counts per revolution, drive the various axes.

The three-axis gantry system is controlled using a Delta Tau Turbo PMAC card (Delta Tau Data Systems Inc., Chatsworth, CA, USA) which operates the motion subsystem through G \& M code via PEWIN 32 software (Delta Tau Data Systems Inc., Chatsworth, CA, USA) running on a personal computer.As discussed in section 2.2, the G \& M code is generated by the indigenously developed tool-path planning software.

\subsubsection{Extrusion Subsystem}

The extrusion subsystem is the core of the entire system and greatly affects the properties of the final products. Li et al. [43]investigated three mechanisms, i.e., a ram extruder, a needle 
valve and an auger valve, to extrude viscous suspensions. The results of that study indicated that the auger valve mechanism provided the most consistent flowrate and thehighest quality extrusion-on-demand. Accordingly, the same extrusion subsystem was used in this study.

Figure 6shows a schematic of the auger valve. The material is delivered by pressurized air to the auger chamber, and extruded by the rotating auger. The extrusion flowrate is controlled by the rotational speed of aservomotor driving the auger. Figure 7shows the auger valve (Preeflow eco-PEN 300, ViscoTec Inc.,Kennesaw, GA, USA) and its controller (eco-CONTROL EC200K, ViscoTec Inc., Kennesaw, GA, USA) used in this study.

The eco-PEN 300 auger valve is a progressive cavity pump based dispenser which employs the "endless piston principle" technology[44]. It consists of a helical metal rotor and an elastomeric stator with double-helix holes which create several sealed cavities between them and progress down or up when the rotor turns. Every cavity has a particular volume, so a specific volume is being extruded with each rotation. The intricate geometry of the rotor and stator makes them taper and overlap, and ensures the cavities alternate to provide continuous and non-pulsing extrusion. This technology is capable of handling materials with a wide range of viscosities $\left(10^{-3}\right.$ to $10^{3} \mathrm{~Pa} \cdot \mathrm{s}$ ) including abrasive and shear sensitive materials[45].

The eco-CONTROL EC200-K controller is a separate desktop controller whichcontrols the degrees of rotor rotation and the rotor speed to extrude specific volumes or continuous filaments at a specified flowrate. At the end of the extrusion, the rotor can be reversed shortly to avoid dripping. The controller can be either operated independently with its menu interface or connected via I/O ports to the host controller.

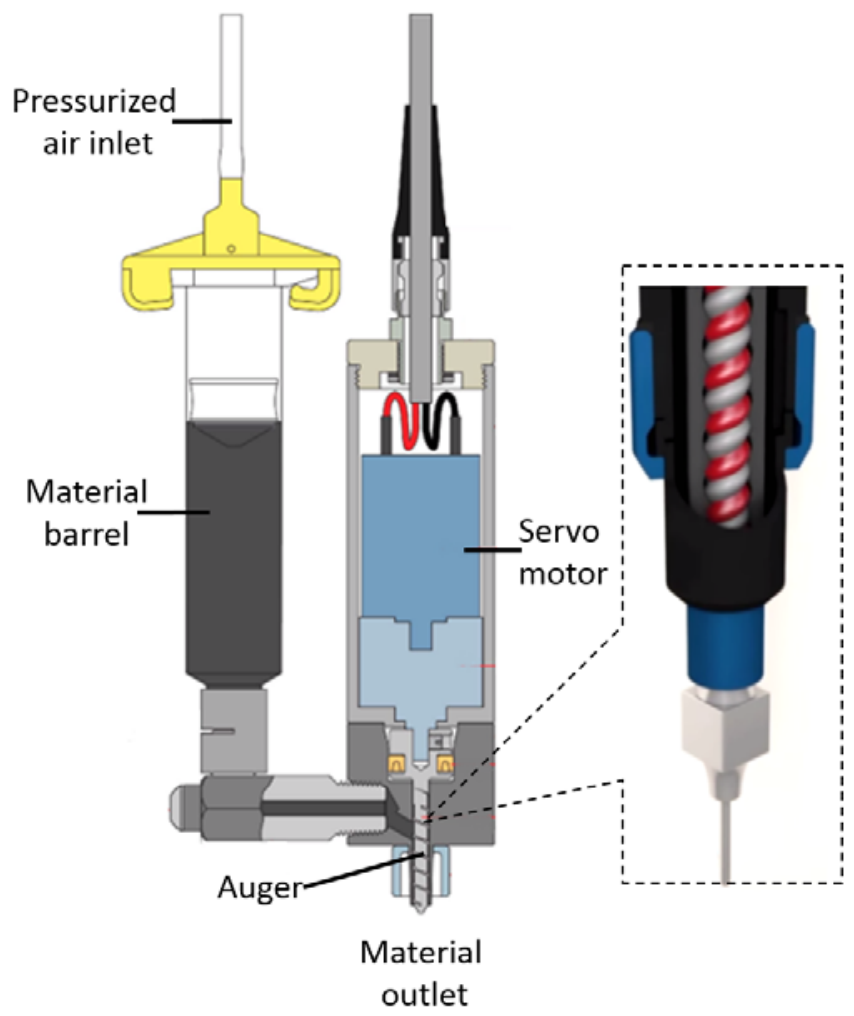

Figure 6. Schematic of an auger valve[46,47]. 


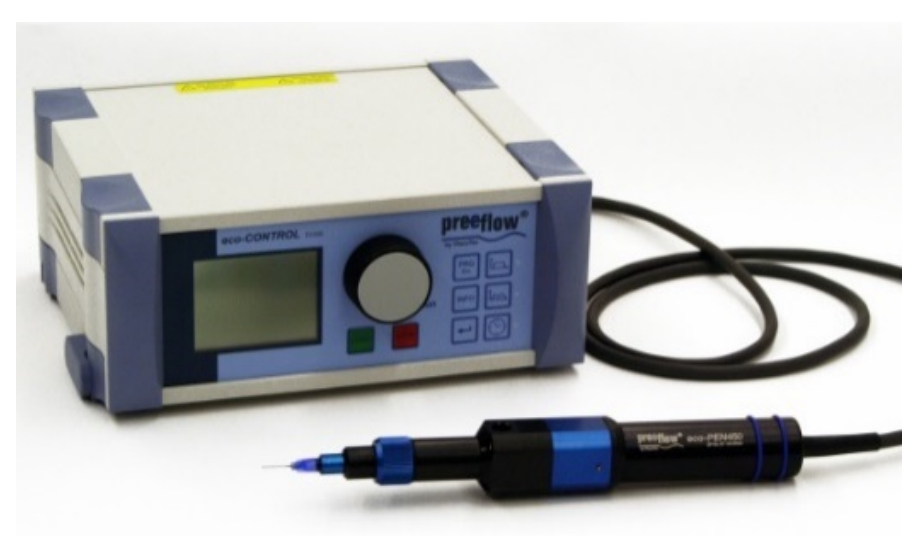

Figure 7. An auger valve and its controller[45].

\subsubsection{Oil Filling Subsystem}

The oil filling subsystem focuses on maintaining the appropriate oil level in the build tank after each layer is extruded. A mineral oil (FlorasenseLamp Oil, MVP Group International Inc., Charleston, SC, USA) was chosen as the liquid surrounding the part to preclude any interaction between the liquid and the paste. The oil level is monitored and controlled by LabVIEW using a closed loop system.The subsystem begins with an input from the G \& M code signaling a desired oil level. The desired oil level is compared to the actual level, given by a level sensor, to produce an error. This error is sent to a PID controller to output a manipulated variable that gives power to a micro gear pumpto control the oil flow rate from the reservoir. A large error in controlling the oil level could be detrimental to the part being fabricated. If too much oil is pumped into the tank, the top surface of the part will be covered by oil and the heat lamp cannot dry that layer. On the other hand, if the amount of oil is not sufficient and thus the oil level is one or more layers below the top layer, cracks and/or warpage might occur on the sides of the part.

\subsubsection{Infrared Heating Subsystem}

After a layer is extruded, the extrusion head returns to its original position in the far-left corner of the build tank to allow time for oil to be dispensed into the tank and the infrared heat source to partially dry the extruded layer. The infrared heating subsystem positions the infrared lamp(375 Watt, 120 Volt, BR40 Clear Heat Lamp Reflector Bulb, Westinghouse Electric Corporation, Philadelphia, PA, USA) above the building tank and turns it on for the amount of time specified in the $G \&$ M code. It then turns the lamp off and moves it away so that the extrusion subsystem can deposit the next layer without interfering with the heating subsystem.

Figure 8shows thermal images from the parts in the build tank during the fabrication process before and after applying heat using the infrared lamp. Clearly, there is a considerable increase in the part temperature $\left(\sim 9^{\circ} \mathrm{C}\right)$ which expedites the drying process. 


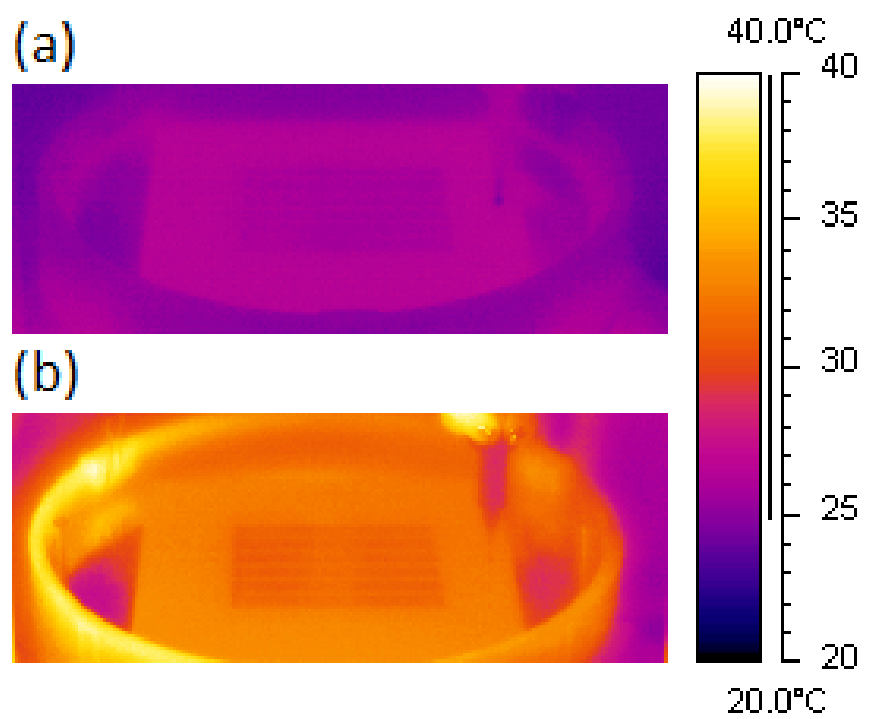

Figure 8. A thermal image of the part and substrate in the tank: (a) before radiation drying and (b) after radiation drying.

\subsubsection{Tuning Process Parameters}

A set of experiments was designed and carried out to obtain the optimum process parameters including nozzle size, nozzle travel speed, rasterspacing, layer thickness, paste flowrate, start dwell time, andearly stop distance. Also, the distance between the lamp and the part, and radiation time of the lamp need to be tuned to evaporate the desired amount of water at the desired rate.

The choice of nozzle diameter depends on the required dimensional accuracy. A smaller nozzle enables printing of finer contours and lines, but prolongs the fabrication time. The extruder used in the CODE system is capable of extruding the paste from nozzles of 150-1000 $\mu \mathrm{m}$ diameter. Most of the sample parts illustrated in this paper (section 3) were fabricated with a $610 \mu \mathrm{m}$ diameter nozzle.

The nozzle travel speed is the speed of the gantry subsystem in the horizontal (XY) plane.Clearly, a higher speed increases the productivity, but decreases the accuracy (due to vibrations and positioning errors of the gantry subsystem). Similar to many freeform extrusion fabrication systems, thebottleneck in achieving higher productivity in the CODE system is also themaximum safe travel speed. At velocities above $\sim 30 \mathrm{~mm} / \mathrm{s}$, there is an observable deviation between the desired tool-path and the actual one. Thus, travel speeds of less than $30 \mathrm{~mm} / \mathrm{s}$ were chosen to fabricate parts.

Raster spacing is the distance between the middle of the two adjacent lines of deposited material. If a solid part is to be printed, this distance should be equal to the width of the lines. Layer thickness is equal to the vertical distance between the nozzle and previous layer/substrate. Obviously, there is a compromisebetween accuracy and productivity when choosing raster spacing and layer thickness. For parts with simple geometry (e.g. bars and blocks), large width and thickness were selected to increase the productivity, and for delicate parts (e.g. gears), small width and thickness values were chosen to increase the dimensional accuracy. With the current 
system, the width can vary from $\sim 200 \mu \mathrm{m}$ to $\sim 1300 \mu \mathrm{m}$ and the thickness can vary between $\sim 100$ $\mu \mathrm{m}$ and $\sim 800 \mu \mathrm{m}$.

The required flowrate of the paste could easily be calculated, based on a continuity equation (using the cross-sectional area of extrudate and travel speed), and controlled, by adjusting the rotational speed of the auger valve. This theoretical value was fine-tuned during experiments to preclude any under/over filling.

Start dwell timeis the time delay between sending a command to the auger valve to start extruding, and actual start in flow of paste. This value was measured experimentally by printing dash linesand was used in G\& M codes to pause the motion of the gantry before each start.

There is also a delay between sending a command to the auger valve to stop extruding, and actual stop in flow of paste. The distance that the nozzle moves while extruding paste, after sending a command to stop the extrusion was also measured experimentally by printing dash lines. To compensate for this delay, astop command was sent to the extruder before the nozzle reached the desired stop point.

The distance between the lamp and the part, and radiation time of the lamp, were estimated based on the drying experiments discussed in section 2.4. For a given layer thickness and heat flux density, the minimum required radiation time was obtained so that the amount of evaporation was sufficient to maintain the shape of the part. The same experiments were repeated with higher heat flux densities until a crack was observed in the part. In this way, the maximum heat flux density and minimum radiation time were determined for each layer thickness.

\subsection{Post-Processing}

Once a partwas completely formed, the oil bath was drained and the piece was bulk dried to remove remaining water. The binder was then removed through a burnout process. The calcined or "brown" part was then sintered to obtain a final part.

\subsubsection{Bulk drying}

Two different methods were used to eliminate the remaining water content in the part. In the first approach, water in the part was first frozen and then removed through sublimation by using a freeze dryer (Genesis 25L, VirTis, Stone Ridge,NY, USA). The temperature was set at $-10^{\circ} \mathrm{C}$ and pressure was 2.0Pa (15mTorr) for three days. Humid drying was used as an alternative approach.An environmental chamber (LH-1.5, Associated Environmental Systems, Ayer, MA, USA) was used to control the temperature and humidity during the drying process. After several experiments, $75 \%$ relative humidity at $25{ }^{\circ} \mathrm{C}$ was determined for the first 4-6 hours of drying. This condition guaranteedsafe drying (i.e. no cracks or warpage). After the first stage of drying, shrinkage was completed and higher drying rates could be achieved without introducing flaws by increasing the temperature. Figure 9 shows the drying behavior of a sample part $\left(5 \times 5 \times 2 \mathrm{~cm}^{3}\right)$ for which the drying temperature was held constant (at room temperature) throughout the process. From the figure, 65 hourswas required to dry the part.However, 20 hourswas achievable by increasing the temperature in the second stage. The properties of the parts produced using freeze drying and humid drying are compared in section 4. 


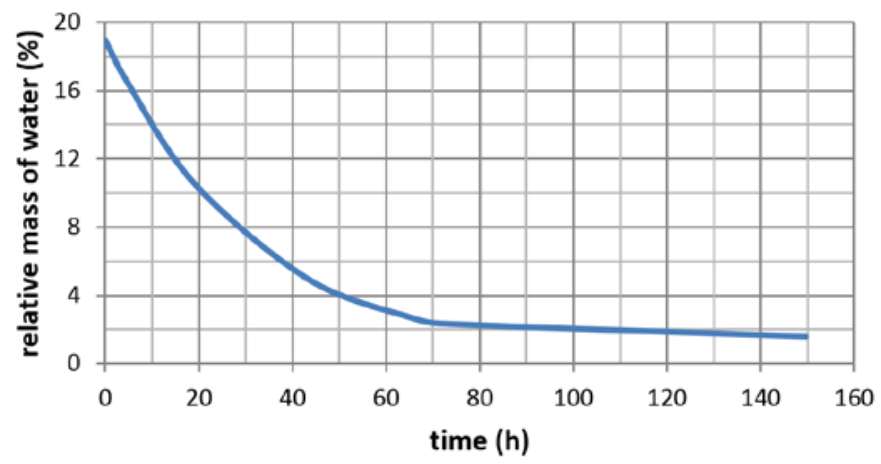

Figure 9. Drying behavior of a sample part at room temperature.

\subsubsection{Binder burnout and sintering}

A heating rate of $1^{\circ} \mathrm{C} / \mathrm{min}$ was chosen for the binder burnout process to avoid high weight reduction rates. The parts were maintained at $450{ }^{\circ} \mathrm{C}$ for two hours. The samples were then densified with a heating rate of $5{ }^{\circ} \mathrm{C} / \mathrm{minin}$ an electric furnace (Deltech Inc., Denver, CO, USA). They were sintered at four different temperatures (1550,1600, 1650 and $1700{ }^{\circ} \mathrm{C}$ ) and two different hold times ( 2 and $5 \mathrm{~h}$ ). The microstructure and density of each group were examined and are discussed in section 4.

\section{Sample Parts}

\subsection{Impeller}

To examine the performance of extrusion-on-demand in practice, fairly complex parts with numerous starts and stops were printed. Figure 10 shows an example of these parts, which is an impeller in the green state. As could be seen from the picture, no visible printing flaw is observed in the part.

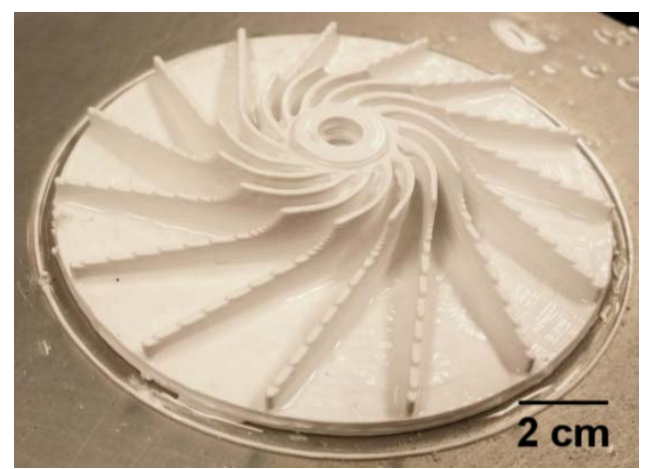

Figure 10. An impeller in the green state.

\section{2. $\underline{\text { Gear }}$}

To investigate the capabilities of the process and system to fabricate solid and monolithic parts with complex geometries, a solid gear was chosen and successfully built. As shown in Figure 11, the part is free of pores between contours and lines. 


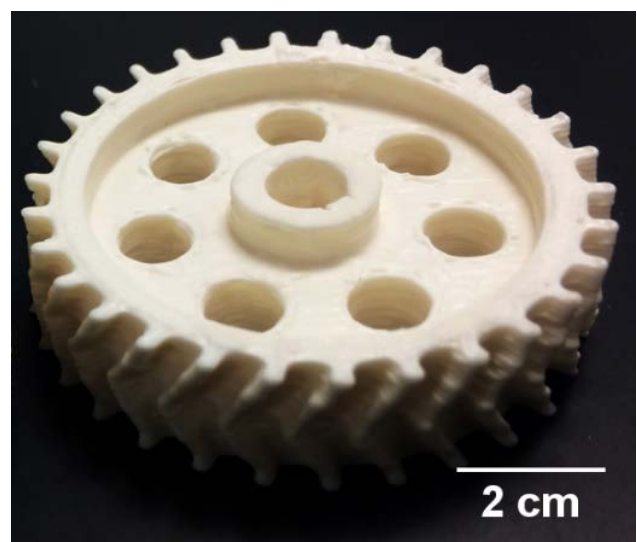

Figure 11. A sintered gear.

\subsection{Smart Refractory Lining Block}

As an application of the CODE process, fabrication of smart refractory linings was considered. It is of prime importance to monitor several parameters (e.g. temperature, pressure, and spalling of walls) in the integrated gasification combined cycle of coal and other carboncontaining fuels. A novel approach to this end is embedding several sensors in the linings of the chamber during the fabrication process. This approach could lead to more accurate measurements, better protection of the sensors, and maintenance of the strength of the linings. Figure 12 demonstrates a lining block in which a mock-up sensor issuccessfully embedded during the fabrication process.

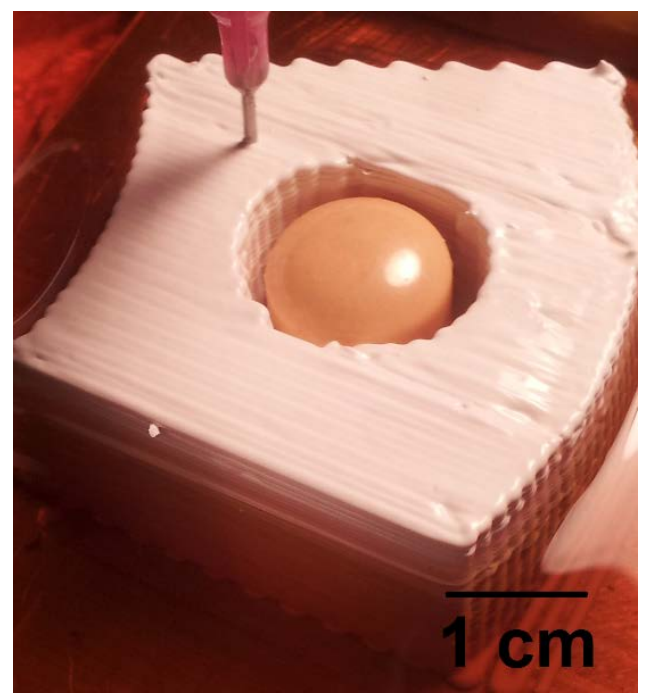

Figure 12. A refractory lining block with embedded mock-up sensor during the fabrication process.

\subsection{Catalyst Support}

An important characteristic of catalyst supports is their surface area to volume ratio. A scaffold structure has a high area to volume ratio; however, it is not feasible to fabricate the structure using traditional manufacturing processes. The CODE process was used to fabricate scaffolds as shown in Figure 13. They were successfully coated with a catalyst as illustrated in Figure 14. 


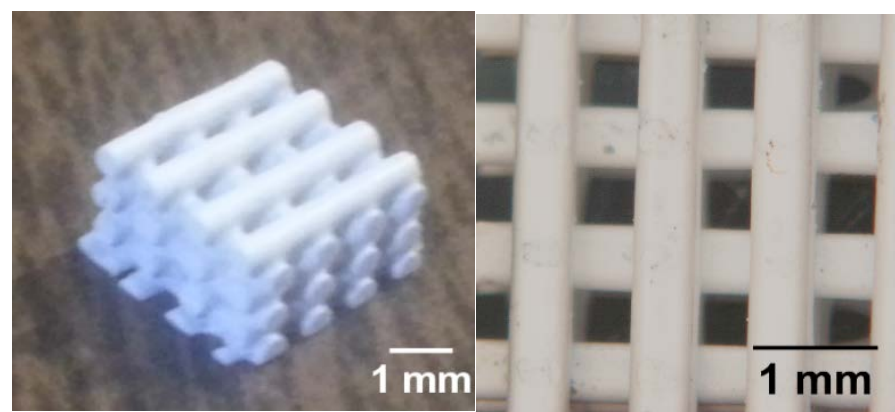

Figure 13. Printed scaffolds beforecoating.

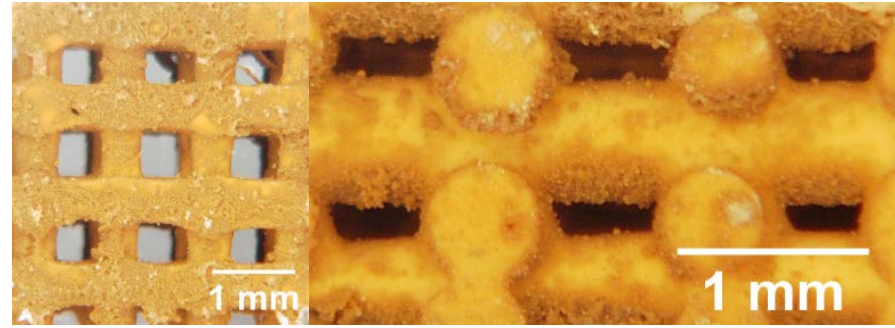

Figure 14. Scaffolds coated with a thin layer of catalyst.

\subsection{Prosthetic Hip Joint}

Alumina is a common material used to produce prosthetic hip joints due to its hardness and biocompatibility [48]. Additive manufacturing of these joints can enable expedited production of custom-made joints at a reasonable cost. A spherical solid part resembling a hip joint was fabricated using the CODE process (seeFigure 15). An advantage of this process is producing relatively strong green parts which could be readily ground to improve the surface quality prior to sintering. Figure 16 shows the same part after manual grinding. Clearly, there is a significant improvement in the surface quality.

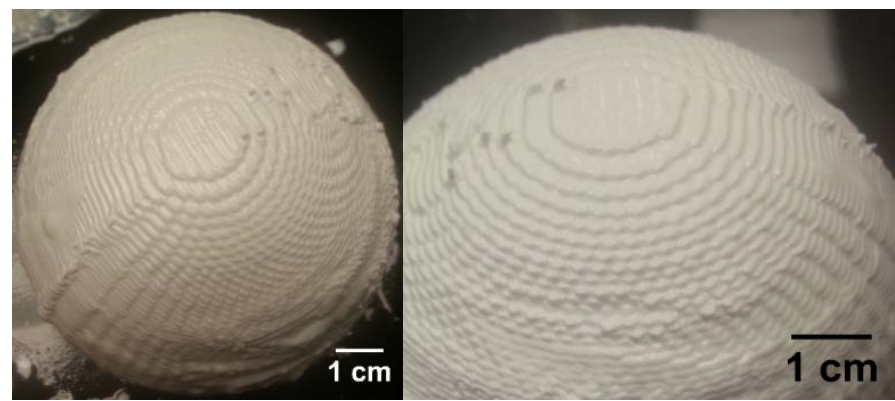

Figure 15. A solid spherical part resembling a prosthetic hip joint in the green state.

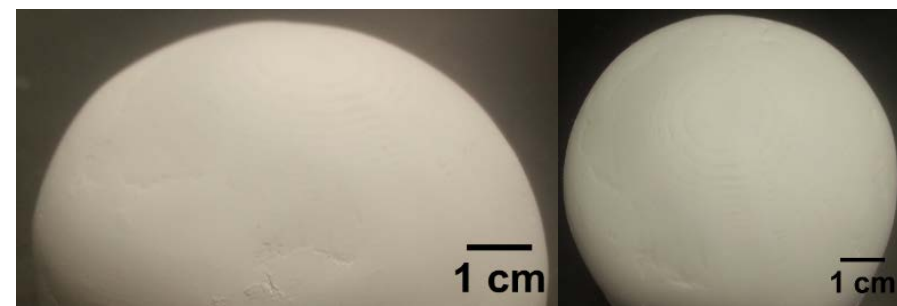

Figure 16. A spherical part aftermanual grinding in the green state. 


\subsection{Higher Resolution Parts}

Clearly, another way to improve the surface quality is using a finer nozzle. Figure 17 shows two sintered parts; the one on top was printed using a nozzle with an internal diameter of 254 $\mu \mathrm{m}$.The bottom part was printed using a nozzle of $610 \mu \mathrm{m}$ diameter.

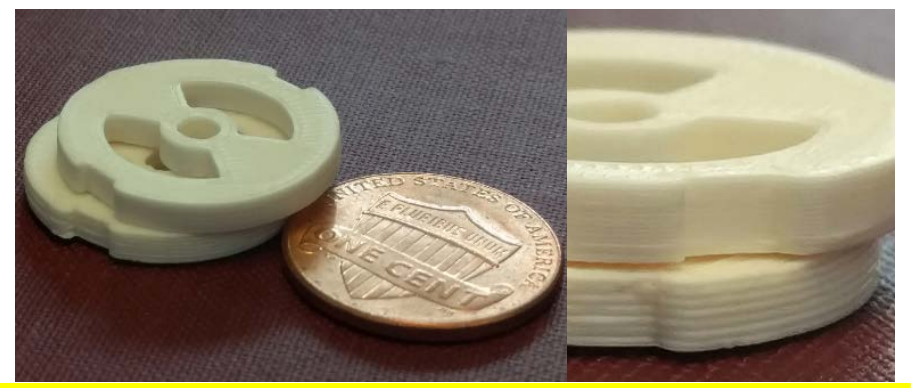

Figure 17. A part printed with a fine nozzle on top of the same part printed with a large nozzle.

\section{Properties of Printed Parts}

\subsection{Density}

Archimedes' technique was used to measure the density of the printed parts after sintering. After the dry mass was recorded, samples were saturated by submersion in distilled water and placing them under vacuum for $12 \mathrm{~h}$. The saturated and suspended masses were then measured to calculate the final density. The results are given in Table 2.

Table 2. Relative density of parts sintered at different schedules.

\begin{tabular}{|c|c|c|c|}
\hline $\begin{array}{c}\text { Sintering } \\
\text { temperature } \\
\left({ }^{\circ} \mathbf{C}\right)\end{array}$ & $\begin{array}{c}\text { Sintering } \\
\text { time (h) }\end{array}$ & $\begin{array}{c}\text { Relative density if } \\
\text { freeze dried (\%) }\end{array}$ & $\begin{array}{c}\text { Relative density if } \\
\text { humid dried (\%) }\end{array}$ \\
\hline 1550 & 2 & - & 97.7 \\
\hline 1550 & 5 & 93.6 & 97.8 \\
\hline 1600 & 5 & 95.7 & 98.5 \\
\hline 1650 & 5 & 97.1 & - \\
\hline 1700 & 5 & 98.2 & - \\
\hline
\end{tabular}

When using the same sintering schedule, the density of freeze dried samples are considerably lower than samples dried in the humid environment. This is partly due to voids caused by ice crystal formation during freezing of samples as discussed in [49]. In addition, expansion of water ( $\sim 9$ vol\%)during freezing results in a lower green body density.Unlike humid drying where ceramic particles are dispersed in a liquid medium and can easily move during drying (causing shrinkage), in freeze drying, particles are not free to move during the drying process. Accordingly, the relative density of freeze dried parts are considerably lower than the humid dried parts (52\% vs. $61 \%)$ and a higher sintering temperature/time is required to densify the freeze dried samples. Nevertheless, if sintered at appropriate conditions, dense parts could be fabricated using the CODE process. The remaining porosity (1.5\%) is attributed to residual air bubbles in the paste and/or binder agglomerates which create voids during binder removal. The size of these defects is typically tens of micrometers. 


\subsection{Microstructure}

Samples were polished to a $0.25 \mu \mathrm{m}$ finish using diamond particles and thermally etched at $1300{ }^{\circ} \mathrm{C}$ for $30 \mathrm{~min}$ to reveal their microstructure. Microstructural analysis was performed using a scanning electron microscope (Helios Nano Lab 600, FEI Corp., Eindhoven, Netherlands). Figure 18 shows the cross-section and microstructure of a printed sample(humid dried and sintered at $1550{ }^{\circ} \mathrm{C}$ for $2 \mathrm{~h}$ ). No printing flaws are observed in these pictures. The grains are equiaxed andsmall $(<5 \mu \mathrm{m})$.

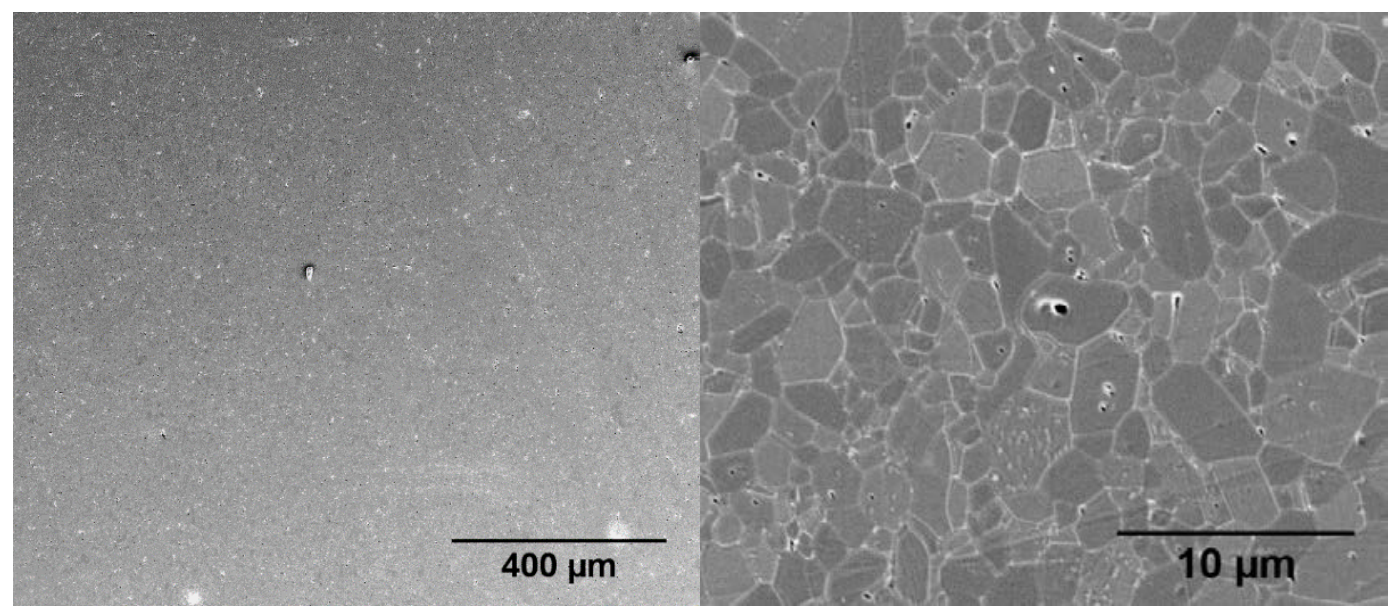

Figure 18. Cross-section and microstructure of a printed sample (humid dried and sintered at $1550{ }^{\circ} \mathrm{C}$ for $2 \mathrm{~h}$ ).

\section{5. $\underline{\text { Conclusions }}$}

A freeform extrusion fabrication process for producing solid ceramic parts was introduced in this paper. The developed tool-path planning software, paste preparation steps,subsystems of the fabrication system, and post-processing were explained. To examine the capabilities of the process, several parts for various applications were built and their density and microstructure studied. The CODE process has been shown to be able to produce large complex parts (up to tens ofcentimeters) with near theoretical density $(>98 \%)$ and a uniform microstructure. Other extensive studies [50-52] demonstrated capabilities of CODE to produce mechanically strong parts from different materials.Other advantages include facile preparation of feedstock, low amount of binder content expediting the post-processing, feasibility of embedding sensors[53], andthe capability of grinding products in the green state.

\section{Acknowledgements}

The authors gratefully acknowledge the financial support by the National Energy Technology Laboratory of the U.S. Department of Energy's Office of Fossil Energy under the contract DEFE0012272, and the Intelligent Systems Center at the Missouri University of Science and Technology.

\section{References}

[1] J. Grau, J. Moon, S. Uhland, M.J. Cima, E. Sachs, High green density ceramic components fabricated by the slurry-based 3DP process, in: Solid Free. Fabr. Symp., 
Austin, TX, USA, 1997: pp. 371-378.

[2] R. Noguera, M. Lejeune, T. Chartier, 3D fine scale ceramic components formed by ink-jet prototyping process, J. Eur. Ceram. Soc. 25 (2005) 2055-2059. doi:10.1016/j.jeurceramsoc.2005.03.223.

[3] E.A. Griffin, S. McMillin, Selective laser sintering and fused deposition modeling processes for functional ceramic parts, in: Solid Free. Fabr. Symp., Austin, TX, USA, 1995: pp. 25-30.

[4] M.L. Griffith, J.W. Halloran, Freeform fabrication of ceramics via stereolithography, J. Am. Ceram. Soc. 79 (1996) 2601-2608. doi:10.1111/j.1151-2916.1996.tb09022.x.

[5] C. Griffin, J. Daufenbach, S. McMillin, Desktop manufacturing: LOM vs pressing, Am. Ceram. Soc. Bull. 73 (1994) 109-113.

[6] N. Travitzky, A. Bonet, B. Dermeik, T. Fey, I. Filbert-Demut, L. Schlier, T. Schlordt, P. Greil, Additive manufacturing of ceramic-based materials, Adv. Eng. Mater. 16 (2014) 729-754. doi:10.1002/adem.201400097.

[7] M.A. Jafari, W. Han, F. Mohammadi, A. Safari, S.C. Danforth, N. Langrana, A novel system for fused deposition of advanced multiple ceramics, Rapid Prototyp. J. 6 (2000) 161-175.

[8] G.E. Hilmas, J.L. Lombardi, R.A. Hoffman, Advances in the fabrication of functionally graded materials using extrusion freeform fabrication, Funct. Graded Mater. (1997) 319324. doi:10.1016/B978-044482548-3/50053-6.

[9] M.C. Leu, B.K. Deuser, L. Tang, R.G. Landers, G.E. Hilmas, J.L. Watts, Freeze-form extrusion fabrication of functionally graded materials, CIRP Ann. - Manuf. Technol. 61 (2012) 223-226. doi:10.1016/j.cirp.2012.03.050.

[10] K. Stuffle, A. Mulligan, P. Calvert, J. Lombardi, Solid freebody forming of ceramics from polymerizable slurry, in: Solid Free. Fabr. Symp., Austin, TX, USA, 1993: pp. 60-63.

[11] R. Vaidyanathan, J. Walish, J.L. Lombardi, S. Kasichainula, P. Calvert, K.C. Cooper, The extrusion freeforming of functional ceramic prototypes, J. Miner. Met. Mater. Soc. (2000) 34-37. doi:10.1007/s11837-000-0066-4.

[12] S.C. Danforth, Fused deposition of ceramics: a new technique for the rapid fabrication of ceramic components, Mater. Technol. 10 (1995) 144-146.

[13] M.K. Agarwala, V.R. Jamalabad, N.A. Langrana, A. Safari, P.J. Whalen, S.C. Danforth, Structural quality of parts processed by fused deposition, Rapid Prototyp. J. 2 (1996) 419. doi:10.1108/13552549610732034.

[14] G.M. Lous, I.A. Cornejo, T.F. McNulty, A. Safari, S.C. Danforth, Fabrication of piezoelectric ceramic/polymer composite transducers using fused deposition of ceramics, J. Am. Ceram. Soc. 83 (2000) 124-128. doi:10.1111/j.1151-2916.2000.tb01159.x.

[15] A. Bandyopadhyay, P.K. Panda, M.K. Agarwala, S.C. Danforth, A. Safari, Processing of piezocomposites by fused deposition technique, J. Am. Ceram. Soc. 80 (1997) 1366-72. doi:10.1111/j.1151-2916.1997.tb02993.x.

[16] A. Safari, M. Allahverdi, E.K. Akdogan, Solid freeform fabrication of piezoelectric 
sensors and actuators, J. Mater. Sci. 41 (2006) 177-198. doi:10.1007/s10853-005-6062-X.

[17] S. Iyer, J. McIntosh, A. Bandyopadhyay, N. Langrana, A. Safari, S.C. Danforth, R.B. Clancy, C. Gasdaska, P.J. Whalen, Microstructural characterization and mechanical properties of Si3N4 formed by fused deposition of ceramics, Int. J. Appl. Ceram. Technol. 5 (2008) 127-137. doi:10.1111/j.1744-7402.2008.02193.x.

[18] J. Cesarano III, R. Segalmen, P. Calvert, Robocasting provides moldless fabrication from slurry deposition, Ceram. Ind. 148 (1998) 94-102.

[19] H.B. Denham, J. Cesarano III, B.H. King, P. Calvert, Mechanical behavior of robocast alumina, in: Solid Free. Fabr. Symp., Austin, TX, USA, 1998: pp. 589-596.

[20] S. Michna, W. Wu, J.A. Lewis, Concentrated hydroxyapatite inks for direct-write assembly of 3-D periodic scaffolds, Biomaterials. 26 (2005) 5632-5639. doi:10.1016/j.biomaterials.2005.02.040.

[21] J. Lewis, J. Smay, J. Stuecker, J. Cesarano, Direct ink writing of three-dimensional ceramic structures, J. Am. Ceram. Soc. 89 (2006) 3599-3609. doi:10.1111/j.15512916.2006.01382.x.

[22] K. Cai, B. Román-Manso, J.E. Smay, J. Zhou, M.I. Osendi, M. Belmonte, P. Miranzo, Geometrically complex silicon carbide structures fabricated by robocasting, J. Am. Ceram. Soc. 95 (2012) 2660-66. doi:10.1111/j.1551-2916.2012.05276.x.

[23] M. Houmard, Q. Fu, M. Genet, E. Saiz, A.P. Tomsia, On the structural, mechanical, and biodegradation properties of HA/ $\beta$-TCP robocast scaffolds., J. Biomed. Mater. Res. B. Appl. Biomater. 101 (2013) 1233-42. doi:10.1002/jbm.b.32935.

[24] T. Schlordt, S. Schwanke, F. Keppner, T. Fey, N. Travitzky, P. Greil, Robocasting of alumina hollow filament lattice structures, J. Eur. Ceram. Soc. 33 (2013) 3243-48. doi:10.1016/j.jeurceramsoc.2013.06.001.

[25] T. Huang, M.S. Mason, G.E. Hilmas, M.C. Leu, Freeze-form extrusion fabrication of ceramics, in: Solid Free. Fabr. Symp., Austin, TX, USA, 2005: pp. 73-85.

[26] T. Huang, G.E. Hilmas, W.G. Fahrenholtz, M.C. Leu, Dispersion of zirconium diboride in an aqueous, high-solids paste, Int. J. Appl. Ceram. Technol. 4 (2007) 470-79.

[27] T. Huang, M.N. Rahaman, N.D. Doiphode, M.C. Leu, B.S. Bal, D.E. Day, Freeze extrusion fabrication of 13-93 bioactive glass scaffolds for repair and regeneration of loadbearing bones, Ceram. Trans. 228 (2011) 45-55. doi:10.1007/s10856-011-4236-4.

[28] A. Li, A.S. Thornton, B. Deuser, J.L. Watts, M.C. Leu, G.E. Hilmas, R.G. Landers, Freeze-form extrusion fabrication of functionally graded material composites using zirconium carbide and tungsten, in: Solid Free. Fabr. Symp., Austin, TX, USA, 2012: pp. 467-79.

[29] A.S. Thornton, Freeze-form extrusion fabrication of boron carbide, Missouri University of Science and Technology, 2014.

[30] M.S. Mason, T. Huang, R.G. Landers, M.C. Leu, G.E. Hilmas, Aqueous-based extrusion of high solids loading ceramic pastes: Process modeling and control, J. Mater. Process. Technol. 209 (2009) 2946-2957. doi:10.1016/j.jmatprotec.2008.07.004. 
[31] X. Zhao, R.G. Landers, M.C. Leu, Adaptive extrusion force control of freeze-form extrusion fabrication processes, J. Manuf. Sci. Eng. 132 (2010) 1-9. doi:10.1115/1.4003009.

[32] B.K. Deuser, L. Tang, R.G. Landers, M.C. Leu, G.E. Hilmas, Hybrid extrusion forcevelocity control using freeze-form extrusion fabrication for functionally graded material parts, J. Manuf. Sci. Eng. 135 (2013). doi:10.1115/1.4024534.

[33] H. Zomorodi, R.G. Landers, Extrusion based additive manufacturing using explicit model predictive control, in: Am. Control Conf., Boston, MA, USA, 2016: pp. 1747-1752.

[34] W. Li, A. Ghazanfari, D. McMillen, M. Leu, G. Hilmas, J. Watts, Fabricating ceramic components with water dissolvable support structures by the ceramic on-demand extrusion process, CIRP Ann. - Manuf. Technol. (2017).

[35] A. Ghazanfari, W. Li, M.C. Leu, Adaptive rastering algorithm for freeform extrusion fabrication processes, Virtual Phys. Prototyp. 10 (2015) 163-172. doi:10.1080/17452759.2015.1096798.

[36] S.W. Sofie, F. Dogan, Freeze casting of aqueous alumina slurries with glycerol, J. Am. Ceram. Soc. 84 (2001) 1459-1464. doi:10.1111/j.1151-2916.2001.tb00860.x.

[37] M.N. Rahaman, Ceramic processing and sintering, Taylor and Francis, Boca Raton, FL, 2007.

[38] F. Lange, Chemical solution routes to single-crystal thin films, Science (80-. ). 273 (1996) 903-909.

[39] E. Santanach Carreras, F. Chabert, D.E. Dunstan, G. V. Franks, Avoiding “mud” cracks during drying of thin films from aqueous colloidal suspensions, J. Colloid Interface Sci. 313 (2007) 160-168. doi:10.1016/j.jcis.2007.03.076.

[40] D.M. Holmes, R. Vasant Kumar, W.J. Clegg, Cracking during lateral drying of alumina suspensions, J. Am. Ceram. Soc. 89 (2006) 1908-1913. doi:10.1111/j.15512916.2006.01053.x.

[41] R.C. Chiu, T.J. Garino, M.J. Cima, Drying of granular ceramic films: I, effect of processing variables on cracking behavior, J. Am. Ceram. Soc. 76 (1993) 2257-2264. doi:10.1111/j.1151-2916.1993.tb07762.x.

[42] K. Narisada, D. Schreuder, Light pollution handbook, volume 1, Springer, Dordrecht, Netherlands, 2004.

[43] W. Li, A. Ghazanfari, M.C. Leu, R.G. Landers, Methods of extrusion on demand for high solids loading ceramic paste in freeform extrusion fabrication, in: D. Bourell, J. Beaman, R. Crawford, S. Fish, H. Marcus, C. Seepersad (Eds.), Solid Free. Fabr. Symp., Austin, TX, USA, 2015: pp. 332-345.

[44] Micro dispensing in perfection, (n.d.). http://www.preeflow.com/media/preeflow2014english.pdf (accessed July 1, 2016).

[45] P. Swanson, The "endless piston" pump technology for precision dispensing, Oxfordshire, England, 2012. http://www.intertronics.co.uk/articles/wp12-1_endless_piston_pumptechnology_for_precision_dispensing.pdf. 
[46] Auger valve dispensing, (2003) 5. https://www.smtnet.com/library/files/upload/EFD__Auger_Valve_Dispensing.pdf (accessed July 1, 2016).

[47] Preeflow one for all, (n.d.). http://www.preeflow.com/en/media- center/videos/ (accessed July 1, 2016).

[48] B.J. McEntire, B.S. Bal, M.N. Rahaman, J. Chevalier, G. Pezzotti, Ceramics and ceramic coatings in orthopaedics, J. Eur. Ceram. Soc. 35 (2015) 4327-4369. doi:10.1016/j.jeurceramsoc.2015.07.034.

[49] J. Li, M.C. Leu, G.E. Hilmas, Effects of temperature on aqueous freeform extrusion fabrication, in: D. Bourell, J. Beaman, R. Crawford, S. Fish, H. Marcus, C. Seepersad (Eds.), Solid Free. Fabr. Symp., Austin, TX, USA, 2015: pp. 319-331.

[50] A. Ghazanfari, W. Li, M. Leu, J. Watts, G. Hilmas, Mechanical characterization of parts produced by ceramic on-demand extrusion process, Int. J. Appl. Ceram. Technol. (2017). doi:10.1111/ijac.12665.

[51] A. Ghazanfari, W. Li, M.C. Leu, J.L. Watts, G.E. Hilmas, Additive manufacturing and mechanical characterization of high density fully stabilized zirconia, Ceram. Int. (2017). doi:10.1016/j.ceramint.2017.01.154.

[52] W. Li, A. Ghazanfari, D. McMillen, M.C. Leu, G.E. Hilmas, J.L. Watts, Properties of partially stabilized zirconia components fabricated by the ceramic on-demand extrusion process, in: D.L. Bourell, R.H. Crawford, C.C. Seepersad, J.J. Beaman, S. Fish, H. Marcus (Eds.), Solid Free. Fabr. Symp., Austin, TX, USA, 2016: pp. 916-928.

[53] A. Ghazanfari, W. Li, M.C. Leu, Y. Zhuang, J. Huang, Advanced ceramic components with embedded sapphire optical fiber sensors for high temperature applications, Mater. Des. 112 (2016) 197-206. doi:10.1016/j.matdes.2016.09.074. 


\section{Figure Captions}

Figure 1. Schematic of the Ceramic On-Demand Extrusion process.

Figure 2. Sequence of printing rasters.

Figure 3. Evaporation curves for $250 \mu \mathrm{m}$ layer.

Figure 4. Evaporation curves for $500 \mu \mathrm{m}$ layer.

Figure 5. Cracks as a result of fast drying.

Figure 6. Schematic of an auger valve [46,47].

Figure 7. An auger valve and its controller [45].

Figure 8. A thermal image of the part and substrate in the tank: (a) before radiation drying and (b) after radiation drying.

Figure 9. Drying behavior of a sample part at room temperature.

Figure 10. An impeller in the green state.

Figure 11. A sintered gear.

Figure 12. A refractory lining block with embedded mock-up sensor during the fabrication process.

Figure 13. Printed scaffolds before coating.

Figure 14. Scaffolds coated with a thin layer of catalyst.

Figure 15. A solid spherical part resembling a prosthetic hip joint in the green state.

Figure 16. A spherical part after manual grinding in the green state.

Figure 17. A part printed with a fine nozzle on top of the same part printed with a large nozzle.

Figure 18. Cross-section and microstructure of a printed sample (humid dried and sintered at $1550{ }^{\circ} \mathrm{C}$ for $2 \mathrm{~h}$ ). 